\title{
Scope of Standardized Tests
}

\author{
Raimundo Olfos, Ivan R. Vysotsky, Manuel Santos-Trigo, \\ Masami Isoda and Anita Rampal
}

The aim of the Discussion Group was to capture the sense of the community about standardized testing and provide implications to global policies. One of the regular views reads as follows: Standardized tests are needed because they can provide a high amount of information and evidence of validity. Of course there can be incorrect interpretations, but these can be reduced if the quality of the test fulfills the requirements that are associated with standardized assessments. Critical approaches highlight other issues: The limited scope of standardized tests in school math, because these tests undermine abilities to conjecture and to encourage open problems in class. Standardized testing devalues abilities to collaborate and to engage in real-world experience, thereby failing the mission of the pursuit of happiness and justice of all. Ethics issues are unsolved: policymakers do not know how to use test-based incentives. Some school systems are under great pressure to raise their scores. Tests create competition between schools. Standardized testing does not take into account diversity, test anxiety, home language of students and special needs. So they fail in democratic systems.

These ideas were shared in two sessions on Tuesday, 26 July, and Friday, 29 July 2016. In a plenary format, Raimundo Olfos introduced the aims and structure of the discussion, followed by a discussion amongst the participants. Masami Isoda presented some clarifications about standardized testing and Ivan Vysotsky problematized their political potential. Ethical consequences of standardized tests were commented on by Anita Rampal, and participants shared their vision and contributed with new ideas. Valeria Di Martino referred to multicultural classrooms and standardized tests in mathematics. Audrey Paradis commented on the use of

\footnotetext{
R. Olfos ( $\square)$

Pontificia Universidad Católica de Valparaíso, Valparaíso, Chile

e-mail: raimundo.olfos@pucv.cl; raimundo.olfos@gmail.com

(C) The Author(s) 2017

G. Kaiser (ed.), Proceedings of the 13th International Congress on Mathematical

Education, ICME-13 Monographs, DOI 10.1007/978-3-319-62597-3_100
} 
standardized tests in terms of teacher perception. Federica Ferretti, Alice Lemmo, and Francesca Martignone talked about the use of large-scale assessment in teacher education, and Johan Yebbou reflected about the introduction of international assessment studies in a country. Finally, the group shared their views in collaborative writing to provide implications for global policies.

Open Access Except where otherwise noted, this chapter is licensed under a Creative Commons Attribution 4.0 International License. To view a copy of this license, visit http://creativecommons. org/licenses/by/4.0/.

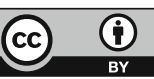

